Article

\title{
Quantitative Structure-Activity Relationships for the Flavonoid-Mediated Inhibition of P-Glycoprotein in KB/MDR1 Cells
}

\author{
Mengmeng Xia ${ }^{\circledR}$, Yajing Fang, Weiwei Cao, Fuqiang Liang ${ }^{\circledR}$, Siyi Pan and Xiaoyun $\mathrm{Xu}^{*}$ * \\ Key Laboratory of Environment Correlative Dietology (Huazhong Agricultural University), Ministry of \\ Education, Wuhan 430070, China; xiamengmeng@webmail.hzau.edu.cn (M.X.); fyj@webmail.hzau.edu.cn (Y.F.); \\ weiweicao@webmail.hzau.edu.cn (W.C.); lfqzyw@webmail.hzau.edu.cn (F.L.); Pansiyi@mail.hzau.edu.cn (S.P.) \\ * Correspondence: xuxiaoyun@mail.hzau.edu.cn ; Tel.: +86-27-87671056; Fax: +86-27-87288373
}

Received: 16 April 2019; Accepted: 24 April 2019; Published: 27 April 2019

\begin{abstract}
P-glycoprotein (P-gp) serves as a therapeutic target for the development of inhibitors to overcome multidrug resistance (MDR) in cancer cells. In order to enhance the uptake of chemotherapy drugs, larger amounts of P-gp inhibitors are required. Besides several chemically synthesized P-gp inhibitors, flavonoids as P-gp inhibitors are being investigated, with their advantages including abundance in our daily diet and a low toxicity. The cytotoxicity of daunorubicin (as a substrate of P-gp) to KB/MDR1 cells and the parental KB cells was measured in the presence or absence of flavonoids. A two-dimensional quantitative structure-activity relationship (2D-QSAR) model was built with a high cross-validation coefficient $\left(\mathrm{Q}^{2}\right)$ value of 0.829 . Descriptors including vsurf_DW23, E_sol, Dipole and vsurf_G were determined to be related to the inhibitory activity of flavonoids. The lack of 2,3-double bond, 3'-OH, 4'-OH and the increased number of methoxylated substitutions were shown to be beneficial for the inhibition of P-gp. These results are important for the screening of flavonoids for inhibitory activity on P-gp.
\end{abstract}

Keywords: flavonoids; P-gp; inhibitory activity; QSAR

\section{Introduction}

P-glycoprotein (P-gp) is a member of the ATP-binding cassette (ABC) family, which is encoded by the $A B C B 1$ gene. The overexpression of P-gp has been associated with multidrug resistance (MDR) in cancer cells, a limiting factor in the success of cancer chemotherapy. Given the role of P-gp in influencing cancer chemotherapy, methods to overcome P-gp-mediated efflux have been investigated. It is generally believed that the mechanisms of P-gp inhibition mainly comprise four aspects: competitively, non-competitively or allosterically blocking the drug binding site; interfering with the ATP hydrolysis process; altering the integrity of cell membrane lipids; decreasing the P-gp expression [1]. Four generations of P-gp inhibitors have been identified in recent years. The first-generation inhibitors, including verapamil [2] and cyclosporine A [3], were found to possess high toxicity at their effective doses [4]. The derivatives of the first-generation inhibitors, dexverapamil and VX710, are termed the second-generation inhibitors. However, due to their impact on P450 and drug interaction profiles, these inhibitors were not used clinically [5]. Elacridar, tetrandrine, and zosuquidar, the third-generation inhibitors, are limited due to their low survival [6]. Therefore, high-potency and low-toxicity P-gp inhibitors are urgently required for chemotherapy treatment. Compounds from natural products belonging to the fourth-generation P-gp inhibitors are of great significance [7].

Flavonoids are a class of compounds based on the diphenylpropane (C6-C3-C6) skeleton, which are widespread in our common diet, including in fruits and vegetables. Flavonoids have been 
shown to be beneficial to human health for their antioxidant, anti-inflammatory, anticarcinogenic and antiviral activities [8]. Several studies have suggested that flavonoids can inhibit P-gp in order to enhance the bioavailability and uptake of anticancer drugs [9]. Flavonoids (biochanin A, morin [10], silymarin [10,11], quercetin [11-13], kaempferol [11-14] and tangeretin [15]) have been demonstrated to present inhibitory activity on P-gp. Kitagawa [16], by studying the structure-activity relationships (SARs) of flavonoids, found that the planar structure and hydrophobic nature of flavonoids are important for the inhibitory effect on P-gp. Quantitative structure-activity relationships (QSARs) can be used for observing the mechanisms between molecular structures and various biological activities [17]. QSAR has been widely used to determine whether a compound is an inhibitor of P-gp. Various studies have built the three-dimensional quantitative structure-activity relationships (3D-QSAR) model to investigate the inhibitory activity on P-gp [18-20]. The model is limited as it is based on the assumption that compounds all act on the same receptor. Furthermore, the 3D-QSAR model is affected by the quality of molecular alignments/superimpositions and information on ligand bioactive conformations [21]. The two-dimensional quantitative structure-activity relationships (2D-QSAR) model does not require subjective (or time-consuming) molecular alignment or putative binding conformation or determination of 3D structures. Furthermore, 2D-QSAR is simple and robust but has been rarely reported.

The aim of this study was to investigate the quantitative structure-activity relationship for the flavonoid-mediated inhibition of P-gp in KB/MDR1 cells overexpressed with P-gp. Daunorubicin [22] has been reported to be an anticancer drug and the substrate P-gp. In this study, the inhibitory activity ( $\mathrm{IC}_{50}$ of daunorubicin) of 31 flavonoids (Table 1) was measured and used to build the 2D-QSAR model to determine the relationship between flavonoid structure and inhibitory activity. The structure characteristics which interact with P-gp could enhance the uptake of chemotherapy drugs.

Table 1. The chemical structures of 31 flavonoids.

\begin{tabular}{|c|c|c|c|c|}
\hline No & Flavonoids & CAS & Core Structure & Substructure \\
\hline 1 & 5-Methoxyflavone & $42079-78-7$ & & $\mathrm{R}_{5}=\mathrm{OMe}$ \\
\hline 2 & 5,7-Dimethoxyflavone & $21392-57-4$ & & $\mathrm{R}_{5}, \mathrm{R}_{7}=\mathrm{OMe}$ \\
\hline 3 & 5,3'-Dimethoxyflavone & & & $\mathrm{R}_{5}, \mathrm{R}_{3^{\prime}}=\mathrm{OMe}$ \\
\hline 4 & 5,7,3'-Trimethoxyflavone & & & $\mathrm{R}_{5}, \mathrm{R}_{7}, \mathrm{R}_{3^{\prime}}=\mathrm{OMe}$ \\
\hline 5 & $5,7,3^{\prime}, 4^{\prime}$-Tetramethoxyflavone & $855-97-0$ & & $\mathrm{R}_{5}, \mathrm{R}_{7}, \mathrm{R}_{3^{\prime}}, \mathrm{R}_{4^{\prime}}=\mathrm{OMe}$ \\
\hline 6 & Tangertin & $481-53-8$ & & $\mathrm{R}_{5}, \mathrm{R}_{6}, \mathrm{R}_{7}, \mathrm{R}_{3^{\prime}}, \mathrm{R}_{4^{\prime}}=\mathrm{OMe}$ \\
\hline 7 & Chrysin & $480-40-0$ & & $\mathrm{R}_{5}, \mathrm{R}_{7}=\mathrm{OH}$ \\
\hline 8 & Baicalein & $491-67-8$ & & $\mathrm{R}_{5}, \mathrm{R}_{6}, \mathrm{R}_{7}=\mathrm{OH}$ \\
\hline 9 & Wogonin & $632-85-9$ & & $\mathrm{R}_{5}, \mathrm{R}_{7}=\mathrm{OH}, \mathrm{R}_{8}=\mathrm{OMe}$ \\
\hline 10 & Apigenin & $520-36-5$ & & $\mathrm{R}_{5}, \mathrm{R}_{7}, \mathrm{R}_{4^{\prime}}=\mathrm{OH}$ \\
\hline 11 & Luteolin & $491-70-3$ & & $\mathrm{R}_{5}, \mathrm{R}_{7,}, \mathrm{R}_{3^{\prime}}, \mathrm{R}_{4^{\prime}}=\mathrm{OH}$ \\
\hline 12 & Vitexin & $3681-93-4$ & & $\mathrm{R}_{5}, \mathrm{R}_{7}, \mathrm{R}_{4^{\prime}}=\mathrm{OH}, \mathrm{R}_{8}=\mathrm{Cglc}$ \\
\hline 13 & Schaftoside & 51938-32-0 & 0 & $\mathrm{R}_{5}, \mathrm{R}_{7}, \mathrm{R}_{4^{\prime}}=\mathrm{OH}, \mathrm{R}_{6}=\mathrm{Cglc}, \mathrm{R}_{8}=\mathrm{Carb}$ \\
\hline 14 & Galangin & $548-83-4$ & & $\mathrm{R}_{3}, \mathrm{R}_{5}, \mathrm{R}_{7}=\mathrm{OH}$ \\
\hline 15 & Kaempferide & $491-54-3$ & & $\mathrm{R}_{3}, \mathrm{R}_{5}, \mathrm{R}_{7}=\mathrm{OH}, \mathrm{R}_{4^{\prime}}=\mathrm{OMe}$ \\
\hline 16 & Fisetin & $528-48-3$ & & $\mathrm{R}_{3}, \mathrm{R}_{7}, \mathrm{R}_{3^{\prime}}, \mathrm{R}_{4^{\prime}}=\mathrm{OH}$ \\
\hline 17 & Quercetin & $117-39-5$ & & $\mathrm{R}_{3}, \mathrm{R}_{5}, \mathrm{R}_{7}, \mathrm{R}_{3^{\prime}}, \mathrm{R}_{4^{\prime}}=\mathrm{OH}$ \\
\hline 18 & Morin & $480-16-0$ & & $\mathrm{R}_{3}, \mathrm{R}_{5}, \mathrm{R}_{7}, \mathrm{R}_{2^{\prime}}, \mathrm{R}_{4^{\prime}}=\mathrm{OH}$ \\
\hline 19 & Isorhamnetin & $480-19-3$ & & $\mathrm{R}_{3}, \mathrm{R}_{5}, \mathrm{R}_{7}, \mathrm{R}_{4^{\prime}}=\mathrm{OH}, \mathrm{R}_{3^{\prime}}=\mathrm{OMe}$ \\
\hline 20 & Myricetin & $529-44-2$ & & $\mathrm{R}_{3}, \mathrm{R}_{5}, \mathrm{R}_{7}, \mathrm{R}_{3^{\prime}}, \mathrm{R}_{4^{\prime}}, \mathrm{R}_{5^{\prime}}=\mathrm{OH}$ \\
\hline 21 & Rutin & $153-18-4$ & & $\mathrm{R}_{3}=\mathrm{ORG}, \mathrm{R}_{5}, \mathrm{R}_{7}, \mathrm{R}_{3^{\prime}}, \mathrm{R}_{4^{\prime}}=\mathrm{OH}$ \\
\hline 22 & Liquiritigenin & $578-86-9$ & & $\mathrm{R}_{7,}, \mathrm{R}_{4^{\prime}}=\mathrm{OH}$ \\
\hline 23 & Naringenin & $480-41-1$ & & $\mathrm{R}_{5}, \mathrm{R}_{7}, \mathrm{R}_{4^{\prime}}=\mathrm{OH}$ \\
\hline 24 & Hesperetin & $520-33-2$ & & $\mathrm{R}_{5}, \mathrm{R}_{7}, \mathrm{R}_{3^{\prime}}=\mathrm{OH}, \mathrm{R}_{4^{\prime}}=\mathrm{OMe}$ \\
\hline 25 & Taxifolin & 24198-97-8 & & $\mathrm{R}_{3}, \mathrm{R}_{5}, \mathrm{R}_{7}, \mathrm{R}_{3^{\prime}}, \mathrm{R}_{4^{\prime}}=\mathrm{OH}$ \\
\hline 26 & Dihydromyricetin & $27200-12-0$ & & $\mathrm{R}_{3}, \mathrm{R}_{5}, \mathrm{R}_{7}, \mathrm{R}_{3^{\prime}}, \mathrm{R}_{4^{\prime}}, \mathrm{R}_{5^{\prime}}=\mathrm{OH}$ \\
\hline
\end{tabular}


Table 1. Cont.

\begin{tabular}{|c|c|c|c|c|}
\hline No & Flavonoids & CAS & Core Structure & Substructure \\
\hline 27 & Silibinin & $22888-70-6$ & & \\
\hline 28 & Daidzein & $40957-83-3$ & & $\mathrm{R}_{7}, \mathrm{R}_{4^{\prime}}=\mathrm{OH}$ \\
\hline 29 & Puerarin & $3681-99-0$ & & $\mathrm{R}_{7}, \mathrm{R}_{4^{\prime}}=\mathrm{OH}, \mathrm{R}_{8}=\mathrm{Cglc}$ \\
\hline 30 & Genistein & $446-72-0$ & & $\mathrm{R}_{5}, \mathrm{R}_{7}, \mathrm{R}_{4^{\prime}}=\mathrm{OH}$ \\
\hline 31 & Biochanin A & $491-80-5$ & & $\mathrm{R}_{5}, \mathrm{R}_{7}=\mathrm{OH}, \mathrm{R}_{4^{\prime}}=\mathrm{OMe}$ \\
\hline
\end{tabular}

\section{Results}

\subsection{Cytotoxicity}

The reversal effect (represented by $\mathrm{IC}_{50}$ ) of flavonoids on the cytotoxicity of daunorubicin to $\mathrm{KB}$ and $\mathrm{KB} / \mathrm{MDR} 1$ cells is shown in Table 2. A decrease in $\mathrm{IC}_{50}$ value indicates a higher flavonoid inhibitory activity. Elacridar $(10 \mu \mathrm{M})$ was used as a positive control. The $\mathrm{IC}_{50}$ values of daunorubicin as a negative control (without any inhibitors) in KB cells were significantly lower compared to those in KB/MDR1 cells, suggesting that daunorubicin is less sensitive to KB/MDR1 cells due to the overexpression of P-gp. Elacridar significantly enhanced the cytotoxicity of daunorubicin in KB/MDR1 cells, being more pronounced in $\mathrm{KB} / \mathrm{MDR} 1$ cells $\left(\mathrm{RF}_{\mathrm{KB} / \mathrm{MDR} 1}=6.818\right)$ compared to $\mathrm{KB}$ cells $\left(\mathrm{RF}_{\mathrm{KB}}=1.512\right)$. As shown in Table 2, the KB/MDR1 cells showed 10-fold and 21-fold resistance to daunorubicin compared to the $\mathrm{KB}$ cells of 17 (quercetin) and $\mathbf{2 8}$ (daidzein), respectively, indicating that quercetin and daidzein can increase the sensitivity of KB/MDR1 cells to anticancer drug substrates. However, the fact that the $\mathrm{RF}_{\mathrm{KB} / \mathrm{MDR} 1}$ of quercetin and daidzein was 0.580 and 0.704 , respectively, indicated an increased P-gp function, while their RFKB was as high as 10.414 and 3.531. These results may be due to the fact that although there is no P-gp expression in KB cells, expression of other proteins like multidrug resistance protein (MRP), or breast cancer resistance protein (BCRP) may occur, which also have the same function as P-gp.

In KB/MDR1 cells, flavonoid 9 showed the highest $\mathrm{RF}_{\mathrm{KB} / \mathrm{MDR} 1}, 4.586$, followed by 8 and 4 with $\mathrm{RF}_{\mathrm{KB} / \mathrm{MDR} 1}$ values of 3.613 and 3.443 , respectively. As we know, flavonoids with an $\mathrm{RF}_{\mathrm{KB} / \mathrm{MDR} 1}$ greater than 1.000 are potential inhibitors of P-gp. However, as shown in Table 2, the RF $\mathrm{KB}_{\mathrm{MDR} 1}$ of flavonoids 11, 12 and 29 is less than 1.000; these results suggested that luteolin, vitexin and puerarin are potential activators of P-gp.

Flavonoids 23, 25 and 26 which lack the 2,3-double bond in the $\mathrm{C}$ ring, had a lower $\mathrm{IC}_{50}$ than their corresponding flavone or flavonol. These findings indicated that the 2,3-double bond is unfavorable to the inhibition of P-gp. Comparing the $\mathrm{IC}_{50}$ of flavonoids $1\left(2.373 \mu \mathrm{M}, \mathrm{R}_{5}=\mathrm{OMe}\right), 2\left(1.579 \mu \mathrm{M}, \mathrm{R}_{5}\right.$, $\left.\mathrm{R}_{7}=\mathrm{OMe}\right), 3\left(1.580 \mu \mathrm{M}, \mathrm{R}_{5}, \mathrm{R}_{3^{\prime}}=\mathrm{OMe}\right)$, and $4\left(0.901 \mu \mathrm{M}, \mathrm{R}_{5}, \mathrm{R}_{7}, \mathrm{R}_{3^{\prime}}=\mathrm{OMe}\right)$, we found that with an increased number of methoxylated substitutions, an increased inhibitory activity on P-gp occurred. The structure-affinity relationship implicated that $3^{\prime}-\mathrm{OH}$ and $4^{\prime}-\mathrm{OH}$ are not conducive to the inhibitory activity of flavonoids by comparing $7\left(\mathrm{R}_{3^{\prime}}, \mathrm{R}_{4^{\prime}}=\mathrm{H}\right.$, inhibitor) and $11\left(\mathrm{R}_{3^{\prime}}, \mathrm{R}_{4^{\prime}}=\mathrm{OH}\right.$, non-inhibitor). It was also supported by an inhibitor galangin $\left(\mathrm{R}_{3^{\prime}}, \mathrm{R}_{4^{\prime}}=\mathrm{H}\right)$ and a non-inhibitor quercetin $\left(\mathrm{R}_{3^{\prime}}, \mathrm{R}_{4^{\prime}}=\mathrm{OH}\right)$. 
Table 2. Reversal effect of flavonoids on the cytotoxicity of daunorubicin to KB/MDR1 and KB cell lines.

\begin{tabular}{|c|c|c|c|c|c|}
\hline \multirow{2}{*}{ No } & \multicolumn{2}{|c|}{ KB/MDR1 Cells } & \multicolumn{2}{|c|}{ KB Cells } & \multirow{2}{*}{$\mathbf{R F}$} \\
\hline & $\mathrm{IC}_{50}(\mu \mathrm{M})$ & $\mathrm{RF}_{\mathrm{KB} / \mathrm{MDR} 1}$ & $\mathrm{IC}_{50}(\mu \mathrm{M})$ & $\mathbf{R F}_{\mathrm{KB}}$ & \\
\hline $\mathrm{C}$ & $3.102 \pm 0.441$ & 1.000 & $0.715 \pm 0.056$ & 1.000 & 4.338 \\
\hline E & $0.473 \pm 0.005$ & 6.818 & $0.455 \pm 0.036$ & 1.512 & 0.962 \\
\hline 1 & $2.373 \pm 0.970$ & 1.307 & $0.993 \pm 0.127$ & 0.720 & 2.390 \\
\hline $2^{t}$ & $1.579 \pm 0.05$ & 1.965 & $0.612 \pm 0.107$ & 1.169 & 2.582 \\
\hline 3 & $1.580 \pm 0.23$ & 1.963 & $0.664 \pm 0.051$ & 1.077 & 2.380 \\
\hline $4^{t}$ & $0.901 \pm 0.042$ & 3.443 & $0.955 \pm 0.007$ & 0.749 & 0.943 \\
\hline 5 & $2.752 \pm 0.211$ & 1.127 & $0.905 \pm 0.035$ & 0.790 & 3.041 \\
\hline 6 & $1.884 \pm 0.243$ & 1.646 & $2.610 \pm 0.671$ & 0.274 & 0.722 \\
\hline 7 & $1.685 \pm 0.623$ & 1.841 & $0.916 \pm 0.048$ & 0.780 & 1.839 \\
\hline 8 & $0.859 \pm 0.137$ & 3.613 & $0.413 \pm 0.099$ & 1.731 & 2.079 \\
\hline $9^{t}$ & $0.676 \pm 0.035$ & 4.586 & $0.679 \pm 0.023$ & 1.053 & 0.996 \\
\hline 10 & $3.226 \pm 0.068$ & 0.962 & $1.983 \pm 0.078$ & 0.361 & 1.627 \\
\hline 11 & $5.894 \pm 0.083$ & 0.526 & $1.368 \pm 0.077$ & 0.523 & 4.310 \\
\hline 12 & $5.501 \pm 0.672$ & 0.564 & $0.781 \pm 0.133$ & 0.916 & 7.046 \\
\hline 13 & $1.459 \pm 0.529$ & 2.126 & $0.904 \pm 0.158$ & 0.791 & 1.613 \\
\hline 14 & $1.560 \pm 0.258$ & 1.989 & $0.768 \pm 0.113$ & 0.931 & 2.030 \\
\hline 15 & $2.891 \pm 0.100$ & 1.073 & $1.319 \pm 0.041$ & 0.542 & 2.192 \\
\hline 16 & $2.463 \pm 0.320$ & 1.260 & $1.409 \pm 0.225$ & 0.508 & 1.748 \\
\hline 17 & $5.353 \pm 0.001$ & 0.580 & $0.514 \pm 0.006$ & 1.391 & 10.414 \\
\hline 18 & $1.214 \pm 0.219$ & 2.556 & $0.916 \pm 0.064$ & 0.781 & 1.325 \\
\hline 19 & $2.976 \pm 0.035$ & 1.042 & $1.953 \pm 0.197$ & 0.366 & 1.524 \\
\hline $20^{t}$ & $2.721 \pm 0.067$ & 1.140 & $0.567 \pm 0.069$ & 1.261 & 4.799 \\
\hline 21 & $2.295 \pm 0.054$ & 1.352 & $1.312 \pm 0.114$ & 0.545 & 1.749 \\
\hline $22^{t}$ & $2.803 \pm 0.203$ & 1.107 & $2.439 \pm 0.189$ & 0.293 & 1.149 \\
\hline 23 & $2.076 \pm 0.041$ & 1.494 & $0.335 \pm 0.015$ & 2.138 & 6.205 \\
\hline 24 & $2.084 \pm 0.146$ & 1.489 & $1.513 \pm 0.057$ & 0.473 & 1.377 \\
\hline 25 & $2.371 \pm 0.106$ & 1.308 & $2.703 \pm 0.182$ & 0.264 & 0.877 \\
\hline 26 & $2.611 \pm 0.116$ & 1.188 & $1.127 \pm 0.092$ & 0.635 & 2.317 \\
\hline $27^{t}$ & $1.783 \pm 0.055$ & 1.740 & $0.962 \pm 0.019$ & 0.744 & 1.854 \\
\hline 28 & $4.409 \pm 0.540$ & 0.704 & $0.203 \pm 0.093$ & 3.531 & 21.773 \\
\hline 29 & $3.882 \pm 0.172$ & 0.799 & $2.393 \pm 0.313$ & 0.299 & 1.623 \\
\hline $30^{t}$ & $1.267 \pm 0.108$ & 2.448 & $0.458 \pm 0.072$ & 1.561 & 2.767 \\
\hline 31 & $2.986 \pm 0.298$ & 1.039 & $2.432 \pm 0.227$ & 0.294 & 1.228 \\
\hline
\end{tabular}

C: control, negative control, without any inhibitors; E: elacridar, positive control; ${ }^{\text {t}}$ : Test set.

\subsection{QSAR Study}

The model was obtained utilizing $\mathrm{IC}_{50}$ as the dependent variable and the calculated molecule descriptors as independent variables. The best QSAR model established using a training set consisting of 24 flavonoids and a test set of seven flavonoids is as follows:

$$
\begin{aligned}
& \mathrm{IC}_{50}=0.183 \text { vsurf_DW23 }-0.359 \mathrm{E} \_ \text {sol }-3.181 \text { dipole }+10.627 \text { vsurf_G }-9.859 \\
& \mathrm{R}^{2}=0.892, \mathrm{R}_{\text {adj }}{ }^{2}=0.869, \mathrm{Q}^{2}=0.829, \mathrm{~F}=39.073, p<0.01, \mathrm{RMSE}=0.492, \mathrm{R}_{\text {pred }}{ }^{2}=0.905
\end{aligned}
$$

The correlation matrix between $\mathrm{IC}_{50}$ and related molecular descriptors is shown in Table 3. The descriptors of vsurf_DW23 and E_sol are significantly related to $\mathrm{IC}_{50}$, indicating that vsurf_DW23 and E_sol play an important role in the inhibitory activity of flavonoids. Also, the Pearson correlation coefficient $|r|<0.5$ between each descriptor indicates that the model has not been over-fitted. The square of the correlation coefficient between the experimental and predicted $\mathrm{IC}_{50}$ values reached 0.904 (Figure 1), indicating that the experimental value is consistent with the predicted value. In addition, the model was verified by cross-validation (leave-one-out), and the cross-validation coefficient $\left(\mathrm{Q}^{2}\right)$ was as high as 0.829 , suggesting that the obtained model has great prediction ability. The test set prediction correlation coefficient reached 0.905 , indicating that the model has better external prediction ability. 
Table 3. The Pearson correlation between $\mathrm{IC}_{50}$ and related descriptors.

\begin{tabular}{cccccc}
\hline & IC $_{\mathbf{5 0}}$ & vsurf_DW23 & E_sol & dipole & vsurf_G \\
\hline IC $_{50}$ & 1.000 & $0.674^{* *}$ & $-0.432^{*}$ & -0.297 & -0.041 \\
vsurf_DW23 & & 1.000 & 0.006 & -0.268 & -0.212 \\
E_sol & & & 1.000 & $-0.464^{*}$ & 0.230 \\
dipole & & & & 1.000 & 0.164 \\
vsurf_G & & & & & 1.000 \\
\hline
\end{tabular}

*: Correlation is significant at the 0.05 level, ${ }^{* *}$ : Correlation is significant at the 0.01 level.

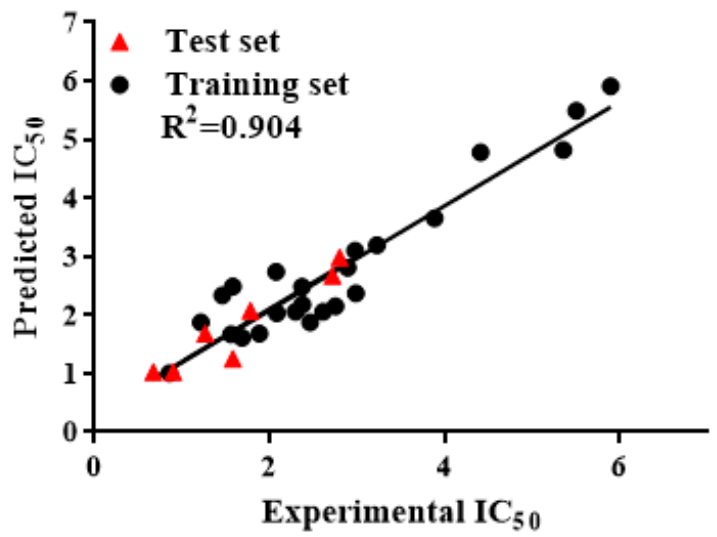

Figure 1. Experimental versus predicted $\mathrm{IC}_{50}$ for the model.

The QSAR model contains two molecular descriptors, E_sol and dipole, which are positively correlated with the inhibitory activity of flavonoids as well as two negatively correlated descriptors, vsurf_DW23 and vsurf_G.

Vsurf_DW23 and vsurf_G are the vsurf_descriptors, which are similar to the VolSurf descriptors. Vsurf_DW23 is a hydrophobic zone parameter that represents the contact distance of vsurf_EWmin (lowest hydrophilic energy) when a water probe interacts with a target molecule [23]. Vsurf_DW23 is positively correlated to $\mathrm{IC}_{50}$, indicating that this descriptor related negatively to the inhibitory activity of flavonoids on P-gp. With increasing $\mathrm{IC}_{50}$ value, the inhibitory activity of flavonoids decreased. As shown in Table 4, it was observed that flavonoids with a vsurf_DW23 value above 10, i.e., 11 (14.221), 17 (11.597), and 28 (16.523), showed high $\mathrm{IC}_{50}$.

The positive contribution of $\mathrm{E}_{-}$sol is the potential energy descriptor that represents the solvation energy. The influence on $\mathrm{IC}_{50}$ of $\mathrm{E} \_$sol is illustrated by comparing the $\mathrm{E} \_$sol and $\mathrm{IC}_{50}$ of flavonoid 16 $(1.410,2.463 \mu \mathrm{M})$ (Table 4$)$ versus $20(-0.215,2.721 \mu \mathrm{M})$. Moreover, flavonoid 12, with a low vsurf_DW23 value (1.118), exhibited a high $\mathrm{IC}_{50}(5.501 \mu \mathrm{M})$ because of the lowest $\mathrm{E}_{-}$sol value $(-11.881)$. We observed that the higher the $\mathrm{E}_{-}$sol value, the smaller the $\mathrm{IC}_{50}$.

Dipole is the conformation-dependent charge descriptor that represents the dipole moment calculated from the partial charges of the molecule. It displays the distribution of charge and the separation degree of negative charge and positive charge [24]. Flavonoid 27 showed a low $\mathrm{IC}_{50}$, but exhibited the highest dipole value due to its structure with four chiral centers. Dipole was positively correlated to $\mathrm{IC}_{50}$, but negatively correlated to the inhibitory activity, as shown in the model.

Vsurf_G is a shape descriptor describing the surface globularity of the molecule [23]. Flavonoid glycosides including 12, 13, 21, and 29 have a high vsurf_G value. Flavonoid 27 also exhibits a high vsurf_G value related to its special structure. Vsurf_G plays an important role in the inhibitory activity on P-gp. 
Table 4. Calculated results using the quantitative structure-activity relationship (QSAR) model.

\begin{tabular}{|c|c|c|c|c|c|c|c|}
\hline No. & vsurf_DW23 & E_sol & dipole & vsurf_G & $\mathrm{IC}_{50}$ (Experimental) & $\mathrm{IC}_{50}$ (Predicted) & Residuals \\
\hline 1 & 0.707 & -3.559 & 0.841 & 1.252 & 2.373 & 2.180 & 0.193 \\
\hline 2 & 1.000 & -3.054 & 1.237 & 1.295 & 1.579 & 1.252 & 0.327 \\
\hline 3 & 1.000 & -3.711 & 0.896 & 1.288 & 1.580 & 2.490 & -0.910 \\
\hline 4 & 1.581 & -2.211 & 1.348 & 1.326 & 0.901 & 1.026 & -0.125 \\
\hline 5 & 1.000 & -1.574 & 0.972 & 1.351 & 2.752 & 2.149 & 0.603 \\
\hline 6 & 3.391 & -0.953 & 1.133 & 1.335 & 1.884 & 1.684 & 0.200 \\
\hline 7 & 1.000 & -4.867 & 1.158 & 1.244 & 1.685 & 1.612 & 0.073 \\
\hline 8 & 0.707 & -2.935 & 1.161 & 1.259 & 0.859 & 1.009 & -0.150 \\
\hline 9 & 1.000 & -4.269 & 1.262 & 1.240 & 0.676 & 1.025 & -0.349 \\
\hline 10 & 1.000 & -5.855 & 0.829 & 1.262 & 3.226 & 3.196 & 0.030 \\
\hline 11 & 14.221 & -5.762 & 0.769 & 1.275 & 5.894 & 5.914 & -0.020 \\
\hline 12 & 1.118 & -11.881 & 0.997 & 1.322 & 5.501 & 5.494 & 0.007 \\
\hline 13 & 0.707 & 1.216 & 0.776 & 1.409 & 1.459 & 2.336 & -0.877 \\
\hline 14 & 0.707 & -0.596 & 0.679 & 1.256 & 1.560 & 1.670 & -0.110 \\
\hline 15 & 0.707 & -0.369 & 0.420 & 1.293 & 2.891 & 2.808 & 0.083 \\
\hline 16 & 0.500 & 1.410 & 0.440 & 1.275 & 2.463 & 1.874 & 0.589 \\
\hline 17 & 11.597 & -0.871 & 0.438 & 1.283 & 5.353 & 4.819 & 0.534 \\
\hline 18 & 0.866 & -3.328 & 1.024 & 1.284 & 1.214 & 1.878 & -0.664 \\
\hline 19 & 3.606 & 0.379 & 0.434 & 1.300 & 2.976 & 3.101 & -0.125 \\
\hline 20 & 0.500 & -0.215 & 0.446 & 1.297 & 2.721 & 2.671 & 0.050 \\
\hline 21 & 1.581 & 0.317 & 1.021 & 1.410 & 2.295 & 2.055 & 0.240 \\
\hline 22 & 1.000 & -2.655 & 0.523 & 1.258 & 2.803 & 2.982 & -0.179 \\
\hline 23 & 1.000 & -2.064 & 0.551 & 1.264 & 2.076 & 2.740 & -0.664 \\
\hline 24 & 0.500 & -0.711 & 0.690 & 1.293 & 2.084 & 2.032 & 0.052 \\
\hline 25 & 1.118 & -3.043 & 0.796 & 1.278 & 2.371 & 2.483 & -0.112 \\
\hline 26 & 1.000 & -1.461 & 0.793 & 1.292 & 2.611 & 2.054 & 0.557 \\
\hline 27 & 1.000 & -3.440 & 1.426 & 1.416 & 1.783 & 2.071 & -0.288 \\
\hline 28 & 16.523 & -1.351 & 0.657 & 1.244 & 4.409 & 4.782 & -0.373 \\
\hline 29 & 1.000 & -4.664 & 0.811 & 1.339 & 3.882 & 3.652 & 0.230 \\
\hline 30 & 0.500 & -5.127 & 1.167 & 1.253 & 1.267 & 1.681 & -0.414 \\
\hline 31 & 1.000 & -5.328 & 1.082 & 1.277 & 2.986 & 2.369 & 0.617 \\
\hline
\end{tabular}

\section{Discussion}

It is widely reported that the main cause of the low bioavailability of chemotherapy drugs is related to transport of P-gp [25]. The most typical method to characterize the P-gp function is to construct a cell line with the overexpression of P-gp and then to detect inhibitor-mediated differences in the uptake of P-gp substrates. In this study, the positive inhibitor elecridar significantly reduced the sensitivity of KB/MDR1 cells to daunorubicin, even to the same level as KB cells. The results indicated that P-gp was overexpressed in KB/MDR1 cells and functioned normally. This finding is consistent with our previous research [26]. Thus, the evaluation results of the cell are effective.

In the current study, we investigated the cytotoxicity of daunorubicin in KB/MDR1 and KB cells. The KB/MDR1 cells showed a 4.34-fold (Table 2) resistance to daunorubicin compared to the KB cells, when there were no inhibitors, indicating that the uptake of the chemotherapy drug daunourbicin is affected by P-gp. Flavonoids directly or indirectly inhibit P-gp to enhance the bioavailability of daunorubicin. In agreement with previous studies [10,27], flavonoids 13, 18 and 30 showed high inhibitory activity. Our results also indicated that the KB/MDR1 cells showed a 10-fold resistance to daunorubicin compared to the $\mathrm{KB}$ cells exposed to flavonoid $\mathbf{1 7}$, indicating quercetin. The sensitivity of KB/MDR1 cells to anticancer drug substrates was increased, which is consistent with previous studies reporting that quercetin is a potential modulator of P-gp [11-13]. Another study [28] showed that methoxylated substitution and its numbers or sites of the rings are important in the reversal of P-gp-mediated MDR, which is also consistent with our observation that an increased number of methoxylated substitutions resulted in an increased inhibitory activity on P-gp.

In order to determine the molecular properties associated with the inhibitory activity, the QSAR model was built. It was observed that the descriptors of vsurf_DW23 $(p<0.01)$ and E_sol $(p<0.05)$ are 
significantly related to $\mathrm{IC}_{50}$ and the Pearson correlation coefficient $|\mathrm{r}|<0.5$. These results indicated that the model was reliable. The 2D-QSAR showed a high prediction ability and internal stability with $\mathrm{Q}^{2}$ value $(0.829)>0.5$ [29], $\mathrm{R}_{\text {pred }^{2}}{ }^{2}$ value $(0.905)>0.6$ [30].

As seen in the model, vsurf_DW23 was confirmed to be an important factor affecting the inhibitory activity of flavonoids. Vsurf_DW23 is a hydrophobic zone parameter that represents the contact distance of vsurf_EWmin (lowest hydrophilic energy) when a water probe interacts with a target molecule [23]. The model possessing this descriptor shows that the decreased contact distance between the lowest hydrophilic regions is beneficial to the inhibitory activity. It reveals that the hydrophilic regions should be minimal for better activity. We also found that $3^{\prime}-\mathrm{OH}$ and $4^{\prime}-\mathrm{OH}$ are not conducive to the inhibitory activity of flavonoids. Thus, the hydrophilicity of flavonoids is not good for its inhibition of P-gp. Moreover, vsurf_G is one of the negatively correlated descriptors which describes the surface globularity of the molecule. The smaller the molecular surface, the better the inhibitory activity.

Based on previous research in the laboratory [31], we found that E_sol is related to the permeability of flavonoids. E_sol represents the solvation energy. It is known that the compound with higher E_sol is harder to solvate. Thus, the compound with higher E_sol entering the binding domain becomes easier. Flavonoids $\mathbf{1 0}$ and $\mathbf{1 7}$ were reported to be substrates [32] as well as inhibitors of P-gp $[33,34]$. Competing with substrates for binding to P-gp is one of the mechanisms of inhibition of P-gp. This finding is consistant with our results which suggested that E_sol is associated with the inhibitory activity of P-gp. In addition, dipole is a positively correlated descriptor which represents the dipole moment calculated from the partial charges of the molecule.

In conclusion, flavonoids that had high inhibitory activity on P-gp should have small values of vsurf_DW23 and vsurf_G and large values of E_sol and dipole. Daunorubicin was used as the substrate of P-gp in order to investigate the inhibitory activity of flavonoids. The absence of 2,3-double bond and both $3^{\prime}-\mathrm{OH}$ and $4^{\prime}-\mathrm{OH}$, and an increased number of methoxylated substitutions were shown to be beneficial to P-gp inhibition. Therefore, specific flavonoids meet these criteria to be modulators of P-gp.

\section{Materials and Methods}

\subsection{Reagents}

3-(4,5-dimethylthiazol-2-yl)-2 and 5-diphenylte trazolium bromide (MTT) were purchased from Gen-View Scientific Inc. (Calimesa, CA, USA). Flavonoids were purchased from Aladdin Chemistry Co., Ltd. (Shanghai, China) (purity $>98 \%$ ). Elacridar was purchased from MedChemExpress. (New Jersey, USA) (purity $>98 \%$ ) (CAS: 143664-11-3) and used as an inhibitor of P-gp. Daunorubicin hydrochloride was purchased from Tokyo Chemical Industry Co. Ltd. (Tokyo, Japan) (purity > 98\%) (CAS:23541-50-6) and used as a substrate of P-gp. All the compounds were dissolved and diluted to a final concentration of $0.1 \%(v / v)$ DMSO. Fetal bovine serum (FBS) was obtained from Zhejiang Tianhang Biotechnology Co.,Ltd. (Zhejiang, China). Dulbecco's modified essential medium (DMEM) was purchased from Hyclone (Logan, UT, USA). The 96-well plates were purchased from Corning Costar (Cambridge, MA, USA).

\subsection{Cell Culture}

The KB cell line was purchased from Culture Collection of the Chinese Academy of Sciences (Shanghai, China). KB/MDR1 cells were stable, transfected with cDNA of human P-gp, which was confirmed by RT-PCR and Western blotting in our previous study [26]. Both KB and KB/MDR1 cells were grown in DMEM with $10 \% \mathrm{FBS}$, penicillin $(100 \mathrm{U} / \mathrm{mL})$ and streptomycin $(100 \mu \mathrm{g} / \mathrm{mL})$ in $5 \% \mathrm{CO}_{2}$, and $90 \%$ relative humidity at $37{ }^{\circ} \mathrm{C} . \mathrm{KB} / \mathrm{MDR} 1$ cells were grown with $500 \mu \mathrm{g} / \mathrm{mL}$ hygromycin (Roche, Switzerland). 


\subsection{Cytotoxicity Assay}

The cytotoxicity of flavonoids and daunorubicin was determined by MTT assay. The cells were seeded in 96-well plates at a density of $7 \times 10^{3}$ cells/well and incubated in an atmosphere of $5 \% \mathrm{CO}_{2}$ at $37^{\circ} \mathrm{C}$ for $24 \mathrm{~h}$. In order to test the inhibition of flavonoids, cells were treated with daunorubicin $(0-20 \mu \mathrm{M})$ in the absence or presence of flavonoids at the non-cytotoxic concentration $(40 \mu \mathrm{M})$ (Figures S1 and S2) for $24 \mathrm{~h}$. The medium was then removed, and the cells were incubated in a serum-free medium containing MTT reagent $(0.5 \mathrm{mg} / \mathrm{mL})$ for $4 \mathrm{~h}$. DMSO $(150 \mu \mathrm{L} /$ well $)$ was added to dissolve the formazan crystals. A multiskan spectrum microplate reader (Thermo Labsystems, Waltham, MA, USA) was used for measuring absorbance at $490 \mathrm{~nm}$. Since inhibitors can enhance the toxicity of daunorubicin in $\mathrm{KB} / \mathrm{MDR} 1$ cells [35], the reversal fold $\left(\mathrm{RF}_{\mathrm{KB} / \mathrm{MDR} 1}, \mathrm{RF}_{\mathrm{KB}}\right)$ of flavonoids was estimated by comparing the $\mathrm{IC}_{50}$ (concentration of $50 \%$ inhibition) of the daunorubicin in the absence of inhibitors to that obtained in the presence of inhibitors. RF was obtained by comparing the $\mathrm{IC}_{50}$ of daunorubicin in the KB/MDR1 cells and the parental KB cells.

\subsection{D-QSAR Study}

The structures of the 31 flavonoids were drawn by ChemBioDraw ultra 12.0. The initial optimization of these flavonoids was performed by Sybyl X-2.0 (Tripos Inc., St. Louis, MO, USA). The molecular descriptors were calculated by Sybyl X-2.0 and Molecular Operating Environment (MOE) 2009.

The $\mathrm{IC}_{50}$ values of the 31 flavonoids in KB/MDR1 cells, in the range 0.676 to 5.894 (Table 2) were used as the dependent variable for QSAR model construction. Seven flavonoids $(\mathbf{2}, \mathbf{4}, \mathbf{9}, \mathbf{2 0}, \mathbf{2 2}, 27$ and 30) were chosen randomly as the test set; the rest of the flavonoids were used as the training set to construct the model. The best molecular descriptors which filtered through the method of the stepwise multiple linear regression (MLR) were adopted as independent variables to build the model. In order to prevent over-fitting between descriptors, correlation analysis between descriptors was performed, and descriptors with an absolute value of correlation coefficients less than 0.5 were selected [29].

The 2D-QSAR model was constructed utilizing the partial least squares (PLS) in Sybyl X-2.0. In the "leave-one-out" method, the $\mathrm{Q}^{2}$ of the resulting model is calculated in order to test the predictive ability of the model. The predicted $\mathrm{IC}_{50}$ in both the training and test sets was calculated from the QSAR model. For the model to be considered reliable, $\mathrm{Q}^{2}$ should be $>0.5$ [29] and the predictive correlation coefficient $\left(\mathrm{R}_{\text {pred }}{ }^{2}\right)$ for the test set should be $>0.6$ [30]. The best model should have the smallest standard error of estimate (SEE) and the highest $F$ value [18]. $Q^{2}$ value was calculated by the following equation (1):

$$
Q^{2}=1-\frac{\sum_{i=1}^{n}\left(y_{i}-\hat{y}_{i}\right)^{2}}{\sum_{i=1}^{n}\left(y_{i}-\bar{y}\right)^{2}}
$$

$n$ is the number of the sample in the training set, $y_{i}$ and $\hat{y}_{i}$ are the experimental and predicted $\mathrm{IC}_{50}$ of the ith sample, and $\bar{y}$ is the average $\mathrm{IC}_{50}$ of all samples.

Supplementary Materials: The following are available online, Figure S1: The cytotoxicity of flavonoids and elacridar in KB/MDR1 cells, Figure S2: The cytotoxicity of flavonoids and elacridar in KB cells.

Author Contributions: Conceptualization, X.X. and S.P.; methodology, Y.F.; software, Y.F.; validation, M.X., W.C. and F.L.; writing — original draft preparation, M.X.; writing—review and editing, Y.F. and M.X.; data analysis, M.X.

Funding: This research was funded by the National Natural Science Foundation of China, grant number 31471625.

Conflicts of Interest: The authors declare no conflict of interest. 


\section{Abbreviations}

$\begin{array}{ll}\text { P-gp } & \text { P-glycoprotein } \\ \text { MDR } & \text { multidrug resistance } \\ \text { QSAR } & \text { quantitative structure-activity relationships } \\ \text { MRP } & \text { multidrug resistance protein } \\ \text { BCRP } & \text { breast cancer resistance protein } \\ \text { DMEM } & \text { minimum essential medium } \\ \text { MTT } & \text { 3-(4, 5-dimethylthiazol-2-yl)-2, 5-diphenyltetrazolium bromide } \\ \text { FBS } & \text { Fetal bovine serum } \\ \text { PLS } & \text { partial least squares } \\ \text { LSD } & \text { least significant difference }\end{array}$

\section{References}

1. Gadhe, C.G.; Cho, S.J. Flavonoids: An Emerging Lead in the P-glycoprotein Inhibition. J. Chosun Nat. Sci. 2016, 12, 2458-2470. [CrossRef]

2. Tsuruo, T.; Iida, H.; Tsukagoshi, S. Overcoming of vincristine resistance in P388 leukemia in vivo and in vitro through enhanced cytotoxicity of vincristine and vinblastine by verapamil. Cancer Res. 1981, 41, 1967-1972. [PubMed]

3. Twentyman, P.R.; Fox, N.E.; White, D.J. Cyclosporin A and its analogues as modifiers of adriamycin and vincristine resistance in a multi-drug resistant human lung cancer cell line. Brit. J. Cancer. 1987, 56, 55-57. [CrossRef] [PubMed]

4. Gottesman, M.M.; Pastan, I. Clinical trials of agents that reverse multidrug-resistance. J. Clin. Oncol. 1989, 7, 409-411. [CrossRef]

5. Tran, C.D.; Timmins, P.; Conway, B.R.; Irwin, W.J. Investigation of the Coordinated Functional Activities of Cytochrome P450 3A4 and P-Glycoprotein in Limiting the Absorption of Xenobiotics in Caco-2 Cells. J. Pharm. Sci. 2002, 91, 117-128. [CrossRef]

6. Shukla, S.; Wu, C.; Ambudkar, S.V. Development of inhibitors of ATP-binding cassette drug transporters: Present status and challenges. Expert Opin Drug Met. 2008, 4, 205-223. [CrossRef] [PubMed]

7. Mohana, S.; Ganesan, M.; Agilan, B.; Karthikeyan, R.; Srithar, G.; Mary, R.B.; Ambudkar, S.V. Screening dietary flavonoids for the reversal of P-glycoprotein-mediated multidrug resistance in cancer. Mol BioSyst. 2016, 12, 2458-2470. [CrossRef] [PubMed]

8. Middleton, E.; Kandaswami, C.; Theoharides, T.C. The Effects of Plant Flavonoids on Mammalian Cells: Implications for Inflammation, Heart Disease, and Cancer. Pharmacol Rev. 2000, 52, 673-751.

9. Pietro, A.D.; Conseil, G.; Perezvictoria, J.M.; Dayan, G.; Baubichoncortay, H.; Trompier, D.; Barron, D. Modulation by flavonoids of cell multidrug resistance mediated by P-glycoprotein and related $\mathrm{ABC}$ transporters. Cell Mol Life Sci. 2002, 59, 307-322. [CrossRef] [PubMed]

10. Zhang, S.; Morris, M.E. Effects of the Flavonoids Biochanin A, Morin, Phloretin, and Silymarin on P-Glycoprotein-Mediated Transport. J. Pharmacol Exp. Ther. 2002, 304, 1258-1267. [CrossRef]

11. Ferreira, A.; Rodrigues, M.; Fortuna, A.; Falcao, A.; Alves, G. Flavonoid compounds as reversing agents of the P-glycoprotein-mediated multidrug resistance: An in vitro evaluation with focus on antiepileptic drugs. Food Res. Int. 2018, 103, 110-120. [CrossRef] [PubMed]

12. Limtrakul, P.; Khantamat, O.; Pintha, K. Inhibition of P-Glycoprotein Function and Expression by Kaempferol and Quercetin. J. Chemotherapy. 2005, 17, 86-95. [CrossRef]

13. Ofer, M.; Wolffram, S.; Koggel, A.; Spahn-Langguth, H.; Langguth, P. Modulation of drug transport by selected flavonoids: Involvement of P-gp and OCT? Eur. J. Pharm. Sci. 2005, 25, 263-271. [CrossRef] [PubMed]

14. Lies, B.; Martens, S.; Schmidt, S.; Boll, M.; Wenzel, U. Flavone potently stimulates an apical transporter for flavonoids in human intestinal Caco-2 cells. Mol. Nutr. Food Res. 2012, 56, 1627-1635. [CrossRef] 
15. Feng, S.; Yuan, Z.; Yao, X.; Ma, W.; Liu, L.; Liu, Z.; Xie, Y. Tangeretin, a citrus pentamethoxyflavone, antagonizes ABCB1-mediated multidrug resistance by inhibiting its transport function. Pharm. Res. 2016, 110, 193-204. [CrossRef]

16. Kitagawa, S.; Nabekura, T.; Takahashi, T.; Nakamura, Y.; Sakamoto, H.; Tano, H.; Tsukahara, G. Structure-Activity Relationships of the Inhibitory Effects of Flavonoids on P-Glycoprotein-Mediated Transport in KB-C2 Cells. Biol. Pharm. Bull. 2005, 28, 2274-2278. [CrossRef]

17. Santos, R.D.; Kuhnen, C.A.; Yunes, R.A. Molecular Structure and QSAR Study on Antispasmodic Activity of some Xanthoxyline Derivatives. Arch. Pharm. 2006, 339, 227-237. [CrossRef] [PubMed]

18. Wongrattanakamon, P.; Lee, V.S.; Nimmanpipug, P.; Jiranusornkul, S. 3D-QSAR modelling dataset of bioflavonoids for predicting the potential modulatory effect on P-glycoprotein activity. Data in Brief. 2016, 9 , 35-42. [CrossRef]

19. Kupsakova, I.; Rybar, A.; Docolomanský, P.; Drobna, Z.; Stein, U.; Walther, W.; Breier, A. Reversal of P-glycoprotein mediated vincristine resistance of L1210/VCR cells by analogues of pentoxifylline: A QSAR study. Eur. J. Pharm. Sci. 2004, 21, 283-293. [CrossRef]

20. Srivastava, S.; Choudhary, B.S.; Sharma, M.; Malik, R. Pharmacophore modeling and 3D-QSAR studies of galloyl benzamides as potent P-gp inhibitors. Med. Chem. Res. 2016, 25, 1140-1147. [CrossRef]

21. Myint, K.Z.; Xie, X. Recent Advances in Fragment-Based QSAR and Multi-Dimensional QSAR Methods. Int. J. Mol. Sci. 2010, 11, 3846-3866. [CrossRef]

22. Borska, S.; Sopel, M.; Chmielewska, M.; Zabel, M.; Dziegiel, P. Quercetin as a potential modulator of P-glycoprotein expression and function in cells of human pancreatic carcinoma line resistant to daunorubicin. Molecules 2010, 15, 857-870. [CrossRef]

23. Cruciani, G.; Crivori, P.; Carrupt, P.; Testa, B. Molecular fields in quantitative structure-permeation relationships: The VolSurf approach. J. Mol. Struc-theochem. 2000, 503, 17-30. [CrossRef]

24. Yang, R.; Yu, L.; Zeng, H.; Liang, R.; Chen, X.; Qu, L. The Interaction of Flavonoid-Lysozyme and the Relationship between Molecular Structure of Flavonoids and Their Binding Activity to Lysozyme. J. Fluoresc. 2012, 22, 1449-1459. [CrossRef] [PubMed]

25. Gadhe, C.G. Comparative Modeling of Human P-gp NBD2 and Docking and Binding Mode Analysis of 8-Geranyl Chrysin as a P-gp Modulator. J. Chosun. Natural Sci. 2012, 1, 18-21. [CrossRef]

26. Fang, Y.; Xia, M.; Liang, F.; Cao, W.; Pan, S.; Xu, X. Establishment and use of human mouth epidermal carcinoma $(\mathrm{KB})$ cells overexpressing P-glycoprotein to characterize structure requirements for flavonoids transported by the efflux transporter. J. Agr. Food Chem. 2019, 67, 2350-2360. [CrossRef]

27. Castro, A.F.; Altenberg, G.A. Inhibition of drug transport by genistein in multidrug-resistant cells expressing P-glycoprotein. Biochem Pharmacol. 1997, 53, 89-93. [CrossRef]

28. Choi, C.; Kim, J.; Kim, S. Reversal of P-glycoprotein-mediated MDR by 5,7,3' , $4^{\prime}, 5^{\prime}$-pentamethoxyflavone and SAR. Biochem. Bioph. Res. Co. 2004, 320, 672-679. [CrossRef] [PubMed]

29. Fang, Y.; Liu, Y.; Zang, X.; Wu, T.; Qi, X.; Pan, S.; Xu, X. 3D-QSAR and docking studies of flavonoids as potent Escherichia coli inhibitors. Sci Rep.-UK 2016, 6, 23634. [CrossRef]

30. Zhang, S.; We, L.; Bastow, K.; Zheng, W.; Brossi, A.; Lee, K.H.; Tropsha, A. Antitumor Agents 252. Application of validated QSAR models to database mining: discovery of novel tylophorine derivatives as potential anticancer agents. J. Comput aid Mol Des. 2007, 21, 97-112. [CrossRef] [PubMed]

31. Fang, Y.; Cao, W.; Xia, M.; Pan, S.; Xu, X. Study of structure and permeability relationship of flavonoids in Caco-2 cells. Nutrients 2017, 9, 1301. [CrossRef]

32. Fang, Y.; Liang, F.; Liu, K.; Qaiser, S.; Pan, S.; Xu, X. Structure characteristics for intestinal uptake of flavonoids in Caco-2 cells. Food Res Int. 2018, 105, 353-360. [CrossRef] [PubMed]

33. Saeed, M.E.; Kadioglu, O.; Khalid, H.; Sugimoto, Y.; Efferth, T. Activity of the dietary flavonoid, apigenin, against multidrug-resistant tumor cells as determined by pharmacogenomics and molecular docking. J. Nutr. Biochem. 2015, 26, 44-56. [CrossRef] [PubMed] 
34. Shapiro, A.B.; Ling, V. Effect of quercetin on hoechst 33342 transport by purified and reconstituted p-glycoprotein. Biochem Pharmacol. 1997, 53, 587-596. [CrossRef]

35. Szakacs, G.; Varadi, A.; Ozvegylaczka, C.; Sarkadi, B. The role of ABC transporters in drug absorption, distribution, metabolism, excretion and toxicity (ADME-Tox). Drug Discov Today. 2008, 13, 379-393. [CrossRef]

Sample Availability: Samples of the compounds are available from the authors.

(C) 2019 by the authors. Licensee MDPI, Basel, Switzerland. This article is an open access article distributed under the terms and conditions of the Creative Commons Attribution (CC BY) license (http://creativecommons.org/licenses/by/4.0/). 